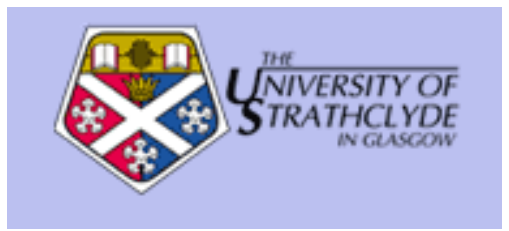

Terzis, S. and Nixon, P. and Wade, V. and Dobson, S. and Fuller, J. (2000) The future of enterprise groupware applications. In: Enterprise Information Systems. Kluwer Academic Publishers, pp. 99-106. ISBN 978-0-7923-6239-5

http://eprints.cdlr.strath.ac.uk/2592/

This is an author-produced version of a book section published in Enterprise Information Systems ISSN 978-0-7923-6239-5.

Strathprints is designed to allow users to access the research output of the University of Strathclyde. Copyright (c) and Moral Rights for the papers on this site are retained by the individual authors and/or other copyright owners. Users may download and/or print one copy of any article(s) in Strathprints to facilitate their private study or for non-commercial research. You may not engage in further distribution of the material or use it for any profitmaking activities or any commercial gain. You may freely distribute the url (http://eprints.collr.strath.ac.uk) of the Strathprints website.

Any correspondence concerning this service should be sent to The Strathprints Administrator: eprints@cis.strath.ac.uk 


\title{
THE FUTURE OF ENTERPRISE GROUPWARE APPLICATIONS
}

\author{
S. Terzis, P. Nixon, V. Wade, S. Dobson, and J. Fuller \\ Computer Science Department, University of Dublin, Trinity College, Dublin 2, Ireland. \\ \{Sotirios.Terzis, Paddy.Nixon, Vincent.Wade, Simon.Dobson, John.Fuller\}@cs.tcd.ie
}

\section{INTRODUCTION}

We are currently witnessing a convergence of several threads of technology and business imperatives. A new model for business organisations, the Virtual Enterprise (VE) is emerging. The new model is based on the idea that business organisations should be able to marshal more resources than they have available without the need for expansion. This, combined with the trend for outsourcing and downsizing, leads to more demanding collaboration between organisations and individuals. As groupware technology focuses on providing enterprise collaboration solutions, the VE model imposes a series of new challenges in the development of enterprise groupware applications.

This paper starts by providing a description of the VE model and identifying the requirements it imposes on future enterprise systems. It continues with a review of groupware technology and products. The purpose of this review is to identify the various aspects that current groupware technology covers and to investigate its appropriateness as the basis for future enterprise systems. Then, it proceeds in an evaluation of the role of groupware in realising the VE model and identifies in which way current technological phenomena will transform groupware and will drive the enterprise systems of the future. Finally, it concludes with a discussion on a new model for developing groupware applications.

\section{VIRTUAL ENTERPRISE MODEL}

A VE is a collection of service providers who collaborate to deliver a new product or service - service that the individual providers cannot offer on their own (see Figure 1). A service is the unit of skill that a collaborator brings into the VE. For example, a skill can be project management expertise, medical expertise, or legal expertise. Typically in a VE, the service providers are not all found within the same organisation. This idea of a business built from both organisationally and geographically distributed units (VE) is becoming an area of increasing interest to both computer scientists and business people because it emerges as a convergence of several threads of technology and business imperatives (Hedberg et. al. 1997). A number of technological phenomena like the WWW, machine independent languages, distributed 
object frameworks, compositional systems and component architectures, as well as business trends like downsizing, outsourcing and just-intime production make VE model both feasible and appealing.

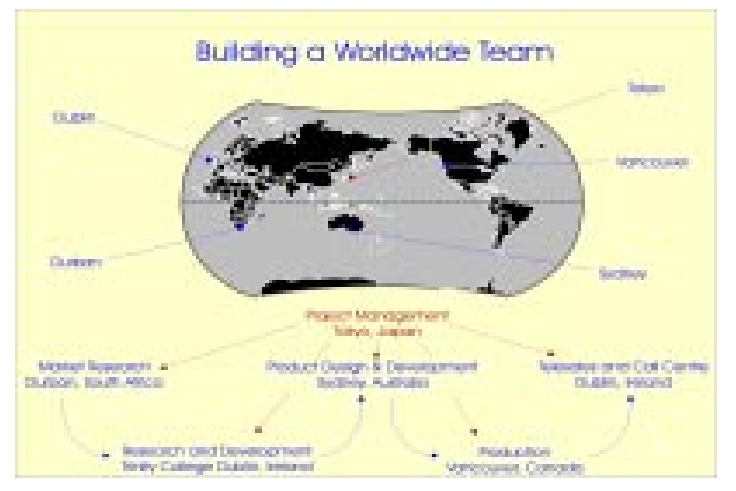

Figure 1. The Virtual Enterprise a worldwide collection of service providers.

The VE model while it provides advantages in almost any business sector, seems especially suitable for small and medium size enterprises (SMEs) in sectors, like manufacturing, telecommunications, healthcare and scientific endeavour. The structure of these sectors is characterised by particularly high vertical and horizontal fragmentation. The vertical fragmentation means that the development of products and services in these sectors requires collaboration between different organisations and individuals. The horizontal fragmentation means that these sectors are highly competitive. So, products in these sectors are characterised by the speed with which they become obsolete, the demand for high responsiveness to highly changeable market conditions and rapid emergence of new niche markets.

Although a number of technological phenomena make the VE model feasible, its effectiveness and efficiency depends on the development of global information infrastructures. These global infrastructures should span organisational boundaries, support dynamic collaboration and composition of services from a worldwide pool, and seamlessly combine existing tools with specialised processes and equipment. Such global infrastructures should be as flexible and easy to use as today's telephone infrastructure.

The requirements for these global information infrastructures can be better demonstrated through the presentation of an example. We choose the case of the healthcare domain because of its importance and distribution of expertise. A patient could move from one doctor or medical centre to the other and his medical record is electronically read and updated. Groups of doctors can be formed dynamically that could include various specialists from all over the world to deal with difficult cases. During the collaboration the people involved might perform different roles. At any time specialised medical equipment could be imported in the process to assist the diagnosis and/or the treatment whenever considered necessary. We should also keep in mind that we have to deal with both emergencies and chronic diseases, so the life span of these groups varies. The medical personnel involved might belong to different organisations and might use different working practises. Serious issues of trust and security in handling the sensitive medical information arise as well as issues of accounting and billing.

From the example presented above we can see the need for dynamic collaboration that the VE model requires. It is our contention that this model will be central to the business organisation of the future. Since groupware technology focuses on collaboration it seems reasonable to examine its current state in order to determine which aspects of the dynamic collaboration requirement covers.

\section{GROUPWARE SURVEY}

The term groupware, although it has a long history, still has different meanings for different people. In order to clarify the term and to provide a better understanding of groupware technology we present a categorisation of groupware research projects and commercial products (see Table 1). The categorisation is based on characteristics they share and services 
they offer. The purpose of the categorisation is not to provide a complete presentation of groupware technology, but to show the various aspects that available groupware applications and research cover.

Examining Table 1 we can identify some common aspects that characterise groupware applications in general. As it is expected in each of these aspects there is a whole range of approaches and each project or product covers a specific part of it. These aspects are the following:

- Communication Strategy. Communication strategy refers to different ways of exchanging information. There are two communication strategies synchronous and asynchronous. Some of the groupware applications support the former (e.g. audio and video conferencing), some the latter (e.g. EMS), and some both (e.g. MSS).

- Co-ordination. Co-ordination refers to the organisation of user interactions. Different group processes require different coordination policies, from flexible ones (e.g. brainstorming session) to rigid ones (e.g. workflow automation).

- Distribution. Distribution refers to the physical location of the group members. The distribution policies manage from physically collocated, to worldwide distributed groups.

- Scalability. Scalability refers to the different group sizes that an application supports. It can range from a few users (e.g. MSS) to a few thousands of users (e.g. web conferencing).

- Openness. Openness refers to the flexibility of a system in integrating other applications, working on different hardware platforms, and the use of different concurrency control and awareness mechanisms.

- Web exploitation. The Web provides a shared information space and supports basic collaboration. Its success, in combination with the usual failures of groupware systems, led to it being considered as an appropriate basis for groupware applications (Bentley et. al. 1997). Thus exploitation of the Web becomes an important aspect of groupware.

- Additional non-functional characteristics. Other non-functional characteristics include things like fault-tolerance, security, safety, integrity, etc. The support of these characteristics and their flexibility differs significantly in the various applications even within the same category.

In the discussion presented above, we identified the support of dynamic collaboration as the basic requirement for the future enterprise systems that will realise the VE model for business organisation. This requirement can be translated, by following the groupware aspects determined above, into a number of functional and non-functional requirements for future enterprise groupware applications. We summarise the functional requirements as follows:

- Support for dynamic group membership;

- Support for dynamic organisational and geographical group member distribution;

- Support for dynamic modes and different ways of communication;

- Support of various group working practices and dynamic group member roles; and

- Support of various types of information exchange.

We also identify the following important non-functional requirements:

- Support of groups with different life duration;

- Integration of currently used tools and support of current working customs; and

- Trust, Authentication and Security issues.

These requirements mean that future enterprise groupware applications need to be able to cover the whole range of each groupware aspects in a way that is flexible and that can dynamically change. So, these requirements can be broadly summarised in two categories: (a) increased flexibility of groupware applications and (b) increased support of dynamism by groupware technology. 
Table 1. Categorisation of Groupware Systems (extended version in Terzis and Nixon 1998).

\begin{tabular}{|c|c|c|c|c|c|}
\hline \multicolumn{4}{|c|}{ Categories of Groupware Systems } & \multirow{2}{*}{\multicolumn{2}{|c|}{$\begin{array}{l}\text { Projects and Products Examples } \\
\text { All current mail systems in various degrees }\end{array}$}} \\
\hline \multirow{2}{*}{$\begin{array}{l}\text { Electronic } \\
\text { Mail } \\
\text { Systems } \\
\text { (EMS) }\end{array}$} & \begin{tabular}{l|l} 
Simple \\
Text
\end{tabular} & \multirow{2}{*}{$\begin{array}{l}\text { Compound } \\
\text { Documents } \\
\text { Hypertext }\end{array}$} & \multirow{2}{*}{$\begin{array}{l}\text { Multimedia } \\
\text { Documents } \\
\text { Advanced } \\
\text { Message } \\
\text { handling }\end{array}$} & & \\
\hline & $\begin{array}{l}\text { Flat } \\
\text { Collections }\end{array}$ & & & Hypermail & CLUES (Marx and Schmandt 1996) \\
\hline \multicolumn{4}{|c|}{ Newsgroups / Bulletin Boards } & \multicolumn{2}{|c|}{$\begin{array}{l}\text { USENET, GroupLens (collaborative filtering see Konstan et. } \\
\text { al. 1997) }\end{array}$} \\
\hline \multicolumn{4}{|c|}{ Message-based Systems } & \multicolumn{2}{|c|}{$\begin{array}{l}\text { Lotus Notes (Lotus Notes 1998), Novell GroupWise (Novell } \\
\text { GroupWise 1998), MS Exchange (MS Exchange 1998), } \\
\text { gIBIS (collaborative design see Conklin and Begeman 1998) }\end{array}$} \\
\hline \multirow{3}{*}{\multicolumn{2}{|c|}{ Conferencing Systems }} & \multicolumn{2}{|l|}{ Text based } & \multicolumn{2}{|c|}{ IRC (Internet Relay Chat), COW (Conferencing On the Web) } \\
\hline & & \multicolumn{2}{|c|}{ Audio Conferencing } & & \multirow{2}{*}{$\begin{array}{l}\text { MBat), COW (Conferencing On the Web) } \\
\text { 1994), Sun ShowMe (Sun ShowMe } \\
\text { 1998), Intel TeamStation (based on } \\
\text { ProShare Technology see Intel } \\
\text { ProShare 1998) }\end{array}$} \\
\hline & & \multicolumn{2}{|c|}{ Video Conferencing } & $\begin{array}{ll}\text { CU-SeeMe } & \text { 1998), Intel TeamStation (based on } \\
\text { (CU-SeeMe 1998) } & \begin{array}{l}\text { ProShare Technology see Intel } \\
\text { ProShare 1998) }\end{array}\end{array}$ & \\
\hline \multicolumn{4}{|c|}{$\begin{array}{l}\text { Meeting Support } \\
\text { Systems (MSS) }\end{array}$} & \multicolumn{2}{|c|}{$\begin{array}{l}\text { MS NetMeeting (MS NetMeeting 1998), NewStar Sound } \\
\text { IDEAS (NewStar 1998), GroCo (Walther 1996), DOLPHIN } \\
\text { (Geiuler et. al. 1995) }\end{array}$} \\
\hline & & \multicolumn{2}{|c|}{$\begin{array}{l}\text { Group Decision Support } \\
\text { Systems } \\
+ \text { Knowledge Management }\end{array}$} & \multicolumn{2}{|c|}{ Object Lens (Kum-Yew et. al. 1988) } \\
\hline \multicolumn{4}{|c|}{ Integrated Group Support Packages } & \multicolumn{2}{|c|}{$\begin{array}{l}\text { Lotus Notes, Novell GroupWise, MS Exchange, Netscape } \\
\text { SuiteSpot (Netscape SuiteSpot 1998), SOFTARC FirstClass } \\
\text { (SOFTARC 1998) }\end{array}$} \\
\hline \multicolumn{4}{|c|}{ Groupware Environments } & \multicolumn{2}{|c|}{ EGRET (Johnson 1994), mStar (Parnes et. al. 1997) } \\
\hline \multicolumn{4}{|c|}{ Workflow Systems } & \multicolumn{2}{|c|}{ Lotus Notes, IBM FlowMark, WebFlow, WWWorkflow } \\
\hline \multicolumn{4}{|c|}{$\begin{array}{l}\text { Shared Editor / Whiteboards } \\
\text { + Co-operative Design Tools (Kyng 1991) }\end{array}$} & \multicolumn{2}{|c|}{$\begin{array}{l}\text { NCSA Collage (NCSA Collage 1997), GroupSketch, } \\
\text { GroupDraw, ConversationBoard }\end{array}$} \\
\hline \multicolumn{4}{|c|}{ Application Sharing (group unaware applications) } & \multicolumn{2}{|c|}{$\begin{array}{l}\text { Colab (Stefik et. al. 1987), XMX (Jones 1993), XTV (Abdel- } \\
\text { Wahab and Feit 1991), GroupX, ShowMe SharedApp, JVTOS } \\
\text { (Joint Viewing and Tele-operation Service) } \\
\text { CoNus (Co-operative Networking for Groups see Reinhard et. } \\
\text { al. 1994) }\end{array}$} \\
\hline \multirow[t]{5}{*}{$\begin{array}{l}\text { Shared } \\
\text { Workspaces }\end{array}$} & & & & \multicolumn{2}{|c|}{$\begin{array}{l}\text { GMD FIT BSCW (Basic Support for Co-operative Work, see } \\
\text { Bentley et. al 1997) }\end{array}$} \\
\hline & Roo & -based systems & & $\begin{array}{l}\text { TeamRooms (Rosema } \\
\text { Mushroom (Kindberg }\end{array}$ & $\begin{array}{l}\text { and Greenberg 1996), } \\
\text { 1996) }\end{array}$ \\
\hline & Virt & 1 Environments (1 & oman 1995) & Virtual Society (Lea e & al. 1997) \\
\hline & $\begin{array}{l}\text { Scie } \\
\text { al. } 1\end{array}$ & ific Collaboratori & (Kouzes et. & $\begin{array}{l}\text { UARC (based on CBE } \\
\text { Tango (Tango 1997) }\end{array}$ & see Jang Ho Lee et. al. 1996), \\
\hline & $\begin{array}{l}\mathrm{MU} \\
(\mathrm{Ob}\end{array}$ & $\begin{array}{l}\text { (Multi User Dung } \\
\text { t Oriented MUD }\end{array}$ & en), MOO & & \\
\hline Aids for & Gro & ware Toolkits & & COAST (Schuckmann & 1996), GroupKit (GroupKit 1998) \\
\hline Groupware & Gro & ware Programmir & Languages & Clock (Graham 1996) & \\
\hline Development & Gro & ware Framework & & $\begin{array}{l}\text { Promondia (Gall and } \mathrm{H} \\
\text { Habanero (NCSA Hab } \\
\text { et. al. 1997) }\end{array}$ & $\begin{array}{l}\text { Jauck 1997), Mushroom, } \\
\text { anero 1996), wOrlds project (Mansfield }\end{array}$ \\
\hline & $\begin{array}{l}\text { Gro } \\
(\mathrm{Gr}\end{array}$ & $\begin{array}{l}\text { Communication } \\
\text { Communication }\end{array}$ & $\begin{array}{l}\text { latforms } \\
1996)\end{array}$ & Totem, Transis, Ramp & art, Horus \\
\hline
\end{tabular}




\section{FUTURE OF GROUPWARE APPLICATIONS}

From the above presented groupware survey, we see that current groupware technology covers every one of the aspects identified above. It fails, though, to provide both the necessary flexibility and the dynamism required for the realisation of the new model. A new perspective in groupware development is the necessary enterprise step forward.

The decomposition of groupware into a set of services, and the viewing of current popular applications also as services, will provide the necessary framework within which this new perspective can be based. This framework should allow the dynamic composition and configuration of these services. It should also allow on-the-fly recomposition and reconfiguration of services. In addition, it should be based on open and widely accepted protocols, in order to overcome the limitations of the current groupware development perspective. Finally, since the number of these services will be significant, the framework should also be scalable.

A number of technological phenomena, described in detail below, will be the driving force towards this new groupware development perspective.

The World Wide Web (WWW) due to its popularity and characteristics (shared information space and communication medium) can be seen as a platform for groupware applications (Bentley et. al. 1997). The number of groupware applications that are either using the WWW or intend to move towards it proves the interest of the groupware community in the Web exploitation (CSCW and the Web 1996). The groupware community hopes that the deployment of the WWW will provide the acceptance base missing currently from groupware technology. On the other hand the web community is (see W3C Collaboration 1995) already tackling the fundamental difficulties in web technology to support groupware applications (Dix 1997). So, it is reasonable to expect that the Web technology and groupware technology will evolve closely together in the future.

Machine-independent languages will be a major driving force for groupware technology, because they tackle hardware dependence; which is a significant groupware problem. In fact a lot of people blame hardware dependence for the inability of groupware applications to gain wide acceptance. The main push towards the use of machine-independent languages was the success of the Java language. Java is also considered to be the language of the WWW, due to the success of Java applets. There are already some groupware applications developed with Java and more are moving towards it every day. It is also important to notice that Java already provides or plans to provide a number of services that will ease the development of groupware applications.

The latest developments in object technology seem to be the third technological push for groupware. The separation of behaviour and presentation that is basic in object-oriented languages allowed the development of customisable groupware and the easy deployment of multimedia objects. The latest developments in object technology are Distributed object frameworks, like the Common Request Broker Architecture (CORBA) by the Object Management Group and Distributed Component Object Model (DCOM) by Microsoft (Baker et. al. 1997). These frameworks allow distributed objects to invoke methods on each other and exchange information in a transparent way, overcoming the intricacies of the various machine, system and language dependencies. They also provide a series of services that allow the location of available objects, simplify the management of objects and ease the development of distributed object systems. Distributed Object frameworks also tackle the problem of tight coupling in distributed systems; opening the road for a new type of software development, component software. 
In component software, applications are created through the composition of interacting components. The important characteristic of these compositional systems is that the same component can be used for the development of different application, thus opening the way for software reuse. Component software also favours the development of components markets where ready made components could be purchased. Since a lot of the groupware applications presented above share common characteristics groupware technology will greatly benefit from the development of component software. A lot of research is devoted in compositional systems and component architectures, which will deal with the difficulties of component development. Component software in combination with the developments in compositional systems and component architectures could provide the framework for the new perspective in groupware development. The research in this area includes projects like Infospheres (The Infospheres Group 1998), Aurora (Marazakis et. al. 1997) and Lotus eSuite (Lotus eSuite 1998). Java technology also moves towards component software with the launch of Enterprise JavaBeans (JavaBeans 1997). CORBA with the development of the component facility and DCOM with the development of ActiveX controls are also moving to the same direction. It is important to note that component software is still in its infancy and that there are a lot of problems that need to be solved (Szyperski 1998).

From the above presentation we can conclude that although the new perspective in groupware development is not immediately feasible there are a number of technologies that could provide a sound basis for it. So, we do not need to reinvent the wheel in enterprise groupware applications. We need to do the necessary steps to enhance software reuse, an often sought but never found goal.

\section{DISCUSSION}

A new model for enterprise organisation, the VE model, is becoming both attractive and feasible. The model requires a new generation of enterprise systems based on groupware technology. Through the presentation of the various groupware categories this paper forms a picture of groupware's scope and thus we identify the major aspects of current groupware technology.

The identification of groupware aspects allowed the definition of enterprise systems requirements, which were summarised as (a) increased flexibility for groupware applications and (b) increased support of dynamism by groupware technology. This translates into support for the full range of groupware aspects, and on the fly exploitation of flexibility.

Although, groupware applications already cover all our aspects, the paper identifies that the requirements dictate a new perspective in groupware development. The driving forces towards this new perspective are:

a) The World Wide Web;

b) Machine-independent languages, like Java;

c) Object technology and distributed object frameworks; and

d) Component software, compositional systems and component architectures.

The significant remark on these technologies is that it is important they realise their influence in groupware and try to add features that will make their deployment by groupware technology easier.

In conclusion, the VE model for enterprise systems although it is not yet immediately feasible, seems to be realistic. The basis for the future enterprise systems is a groupware of the future, and to attain this we need no fundamental changes in groupware technology. What we do need is to "reformulate" groupware functionality into components and to provide the glue to plug them together. To achieve this we need to leverage the convergence of the WWW, 
component architectures and distributed object frameworks.

\section{ACKNOWLEDGEMENTS}

This work was funded by Ireland's National Software Directorate under the Programme in Advanced Technology (PAT), as part of the Virtues Project (http://www.cs.tcd.ie/Virtues/).

\section{REFERENCES}

Abdel-Wahab, H. and Feit, M. 1991, XTV: A framework for sharing $x$ window clients in remote synchronous collaboration, in IEE TriComm '91, April 1991

Baker, S., Cahill, V. and Nixon, P.A. 1997, Bridging Boundaries: Corba in perspective, IEEE Internet Computing, vol. 1, no 5, pp. $52-57$

Bentley, R., Appelt, W., Busbach, U., Hinrichs, E., Kerr, D., Sikkel, S., Trevor, J. and Woetzel, G. 1997, Basic Support for Co-operative Work in the World Wide $W e b$, International Journal of Human-Computer Studies, vol. 46, no. 6: Special issue on Innovative Applications of the World Wide Web, June 1997

Bentley, R., Horstmann, T. and Trevor, J. 1997, The World Wide Web as Enabling Technology for CSCW: The Case of BSCW, Computer Supported Co-operative Work: The Journal of Collaborative Computing 6: 111134

Boman, D. 1995, International Survey: Virtual Environment Research, IEEE Computer, vol. 28, no. 6, June 1995

Conklin, J. and Begeman, M. 1998, gIBIS: A Hypertext Tool for Exploratory Policy Discussion, ACM Transactions on Office Automation, vol. 6, no. 4, October 1988

CSCW and the Web 1996, http://orgwis.gmd.de/projects/W4G/

CU-SeeMe 1998, http://cu-seeme.cornell.edu

Dix, J. 1997, Challenges for Co-operative Work on the Web: An Analytical Approach, Computer Supported Co-operative Work: The Journal of Collaborative Computing 6: 135-156

Eriksson, H. 1994, MBONE: The Multicast Backbone, Communications of the ACM, vol. 37, no. 8, August 1994

Gall, U. and Hauck, F.J. 1997, Promondia: A Java-based Framework for Real-Time Group Communication in the Web, In Proceedings of the $6^{\text {th }}$ International World Wide Web Conference, April 1997

Geiuler, J., Haake, J. M. and Streitz, N. A. 1995, DOLPHIN: A Hypermedia-Based Meeting Support System, Conference Video of the $4^{\text {th }}$ European Conference on Computer Supported Co-operative Work, September 1995

Graham, T.C.N. 1996, The Clock Language: Preliminary Reference Manual, November 1996

Group Communication 1996, Special issue in Group Communication, Communications of the ACM, vol. 39, no. 4, April 1996

GroupKit 1998, http://www.cpsc.ucalgary.ca/projects/grouplab/groupki $\mathrm{t} /$

Hedberg, B., Dahlgren, G., Hansson, J. and Olve, N. 1997, $\bar{V}$ irtual Organisations and Beyond, John Wiley and Sons, pp. 237

Intel ProShare 1998, http://channel.intel.com/proshare/conferencing/

Jang Ho Lee, Prakash, A., Jaeger, T. and Wu, G. 1996, Supporting Multi-Applet Workspaces in CBE, in Proceedings of the ACM 1996 Conference on Computer Supported Co-operative Work

JavaBeans 1997, http://java.sun.com/beans/

Johnson, P. M. 1994, Experiences with EGRET: an exploratory group work environment, Collaborative Computing, vol. 1, no. 1, pp. 87-107

Jones, O. 1993, Multidisplay software in X: A survey of architectures, in The X Resources, vol. 6, O'Reilly \& Associates, Inc.

Kindberg, T. 1996, Mushroom: a framework for collaboration and interaction across the Internet, in Proceedings of the International Workshop on CSCW and the Web, Sankt Augustin, Germany, February 1996

Konstan, J., Miller, B., Maltz, D., Herlocker, J., Gordon, L. and Riedl, J. 1997, GroupLens: Applying Collaborative Filtering to Usenet News, Communications of the ACM, vol. 40, no. 3, March 1997

Kouzes, R. T., Myers, J. D. and Wulf, W. A. 1996, Collaboratories: Doing Science on the Internet, IEEE Computer, vol. 29, no. 8, August 1996

Kum-Yew, L., Malone, T. and Keh-Chiang Yu 1988, Object Lens: A "Spreadsheet" for Co-operative Work, ACM Transactions on Office Information Systems, vol. 6, no. 4, October 1988

Kyng, M. 1991, Designing for Co-operation: Cooperating Design, Communications of the ACM, vol. 34, no. 12, December 1991

Lea, R., Honda, Y. and Matsuda, K. 1997, Virtual Society: Collaboration in $3 D$ Spaces on the Internet, Computer Supported Co-operative Work: The Journal of Collaborative Computing 6: 227-250 
Lotus eSuite 1997, http://esuite.lotus.com/

Lotus Notes 1998, http://www.lotus.com/notes

Mansfield, T., Kaplan, S., Fitzpatrick, G., Phelps, T., Fitzpatrick, M. and Taylor, R. 1997, Evolving Orbit: a progress report on building locales, in Proceedings of the International ACM SIGGROUP Conference on Supporting Group Work, November 1997

Marazakis, M., Papadakis, D. and Nikolaou, C. 1997, Developing Network-Centric Applications by Dynamic Composition of Components", Technical Report TR 213, Institute of Computer Science, FORTH

Marx, M. and Schmandt, C. 1996, CLUES: Dynamic Personalised Message Filtering, in Proceedings of the ACM 1996 Conference on Computer Supported Cooperative Work

MS Exchange 1998, http://www.microsoft.com/exchange

MS NetMeeting 1998, http://www.microsoft.com/netmeeting

NCSA Collage 1997, http://www.ncsa.uiuc.edu/SDG/Software/XCollage/col lage.html

NCSA Habanero 1996, http://www.ncsa.uiuc.edu/SDG/Software/Habanero/

Netscape SuiteSpot 1998, http://www.netscape.com/suitspot

NewStar 1998, http://www.newstartech.com

Novell GroupWise 1998, http://www.novell.com/groupwise

Parnes, P, Synnes, K. and Schefstrom, D. 1997, The CDT mStar environment: Scalable Distributed Teamwork in Action, in Proceedings of the International ACM SIGGROUP Conference on Supporting Group Work, November 1997

Reinhard, W., Schwitzer, J. and Volksen, G. 1994, CSCW Tools: Concepts and Architectures, IEEE Computer, vol. 27, no. 5, May 1994

Roseman, M. and Greenberg, S 1996, TeamRooms: Network Places for Collaboration, in Proceedings of the ACM 1996 Conference on Computer Supported Co-operative Work

SOFTARC 1998, http://www.softarc.com/porduct

Stefik, M., Foster, G., Bobrow, D. G., Kahn, K., Lanning, S. and Suchman, L. 1987, Beyond the chalkboard: Computer Support for collaboration and problem solving in meeting, Communications of the ACM, vol. 5, no. 2, April 1987

Sun ShowMe 1998, http://www.sun.com/products-nsolutions/sw/ShowMe

Szyperski, C. 1998, Component Software: Beyond ObjectOriented Programming, ACM Press, Addisson-Wesley

Tango 1997, Tango Collaboratory for the Web, http://trurl.npac.syr.edu/tango/

Terzis, S. and Nixon, P. 1998, Building the next generation groupware: A survey of groupware and its impact on the virtual enterprise, Technical Report TCD-CS-1998-25, Computer Science Department, University of Dublin, Trinity College
The Infospheres Group 1998, The Infospheres Infrastructure version 2.0 Tutorial, The Infospheres Group, California Institute of Technology

W3C Collaboration 1995, http://www.w3.org/Collaboration/

Walther, M. 1996, Supporting Development of Synchronous Collaboration Tools on the Web with GroCo, Proceedings of the ERCIM workshop on CSCW and the Web, February 1996 